\title{
The Impact of Physiological Interpretation of Cardiotocogram (CTG) in Conjunction with Fetal ECG (STAN) on Intrapartum Emergency Caesarean Sections
}

\author{
Sajitha Parveen ${ }^{1}$, Ewelina Rzyska ${ }^{2}$, Lisa Pilkington ${ }^{3}$ and Edwin Chandraharan ${ }^{4 *}$ \\ ${ }^{1}$ Lead Consultant Labour Ward, Royal Gwent Hospital, UK \\ ${ }^{2}$ Consultant Gynaecologist, University Hospital of Wales, UK \\ ${ }^{3}$ Specialist Trainee in Obstetrics \& Gynaecology, University Hospital of Wales, UK \\ ${ }^{4}$ Director, Global Academy of Medical Education \& Training, UK
}

Submission: May 17, 2021; Published: July 19, 2021

*Corresponding author: Edwin Chandraharan, Director, Global Academy of Medical Education \& Training, UK

Abstract

Background: The false-positive rate of the "pathological" CTG has been reported as $>60 \%$, which resulted in an exponential increase in emergency intrapartum caesarean sections for "fetal distress". Fetal ECG (ST-Analyser or STAN) was introduced into clinical practice to reduce the false positive rate of the CTG.

Objective: To determine the impact of Physiological interpretation of Cardiotocogram (CTG) in Conjunction with Fetal ECG (STAN) on intrapartum emergency caesarean sections.

Materials \& Methods: A retrospective study at the Royal Gwent Hospital in South Wales following the introduction of STAN monitoring after training in Physiological Interpretation of CTG in 2014. Total Caesarean section rate, emergency caesarean section rate for fetal compromise (i.e., "fetal distress"), operative vaginal delivery rate and spontaneous vaginal delivery (SVD) rate were analyzed for the first 19 months after the intervention (October 2014- 2016) and were compared with 2012 -September 2014).

Result: There were 7977 deliveries during the 19-month period from 01 October 2014 to 30 April 2016. The average total Caesarean section rate was $23.5 \%$ and the emergency Caesarean section rate for suspected fetal compromise ("fetal distress") was 13.6\%, an observed increase in the rate of spontaneous vaginal births from $63 \%$ to $71 \%$. There was a statistically significant reduction in the intrapartum emergency caesarean sections performed for "fetal distress" immediately after the introduction of STAN following training on Physiological Interpretation of CTG from $5.57 \%$ to $2.1 \%$. The rate of hypoxic ischaemic encephalopathy (HIE) due to CTG misinterpretation was reduced by $50 \%$ following the training on Physiological Interpretation of CTG.

Conclusion: Training on physiological interpretation of the CTG before the introduction of STAN, and its use in conjunction with STAN resulted in a statistically significant reduction of intrapartum emergency caesarean section for "fetal distress", and a 50\%reduction in the HIE rate due to CTG misinterpretation.

Keywords: Physiological interpretation; Cardiotocograph; Fetal ECG; ST-Analyser; Emergency caesarean section; Hypoxic-ischaemic encephalopathy

Abbreviations: ST: Analyzer (STAN): Cardiotocograph (CTG): Hypoxic-Ischaemic Encephalopathy (HIE); Relative Utero-placental Insufficiency (RUPI)

\section{Introduction}

Cardiotocograph (CTG) was introduced into clinical practice in late 1960s to recognize features of intrapartum fetal hypoxic stress. However, it was introduced into clinical practice without any prior randomized controlled trials or robust observational trials, which resulted in significant confusion about the features that were believed to be suggestive of ongoing fetal compromise. Various guidelines classified CTG traces based on the morphological appearances of decelerations resulting in significant inter and intra-observer variability between clinicians 


\section{Global Journal of Reproductive Medicine}

when they classified CTG traces. Human fetuses are exposed to repetitive mechanical (i.e., head compression and compression of the umbilical cord) and hypoxic (reduction in uteroplacental circulation because of increased intervillous pressure and constriction of the branches of uterine arteries which traverse through the myometrium to supply the placental bed) stresses during uterine contractions. These stresses not only worsen with time as the uterine contractions become progressively stronger and longer as the labor advances, but they may also last for up to 8 to 12 hours. Abnormal and poor placentation, late onset placental failure resulting in a relative uteroplacental insufficiency (RUPI), presence of infection and inflammation (e.g., chorioamnionitis), the rapidity of development of hypoxic stress (e.g., the use of oxytocin for augmentation of labour) may blunt effective fetal compensatory mechanisms predisposing to neurological injury (hypoxic ischaemic encephalopathy or HIE) and perinatal death. Cardiotocograph (CTG) traces are aimed at timely recognition of a fetus at risk of sustaining HIE by scrutinising several "features" on the CTG trace. However, currently there are several national and international guidelines on CTG interpretation which not only have different parameters, different features and different presumed durations, but also, they have different terminologies for classification of CTG traces. The Guidelines produced by the International Federation of Gynecology and Obstetrics (FIGO) [1] and, the National Institute of Health and Care Excellence (NICE) [2] classify CTG traces into "Normal", "Suspicious", "Pathological". The guidelines produced by the American College of Obstetricians and Gynecologists (ACOG) for the interpretation of CTG traces classifies the CTG as "Category 1", "Category II", and "Category III" traces [3]. The revised clinical guideline for the use of fetal ECG (ST-Analyser or STAN) is based on the old FIGO Guidelines of 1987, and classifies the CTG traces into "Normal", "Intermediary", "Abnormal" [4]. The different terminologies and classification systems about intrapartum fetal heart rate monitoring illustrate the degree of confusion regarding the fetal pathophysiological responses to intrapartum hypoxic stress and an evolution of understanding over time resulting in a significant inter-observer [5-7] and intra-observer variation in CTG interpretation [8-10]. Such inter- and intra-observer variability due to the use of these "pattern recognition" guidelines not only may result in poor neonatal outcomes due to under classification and increased intrapartum emergency operative interventions to the mother due to over classification, they may also result in a variation in clinical practice amongst clinicians. Therefore, it is not surprising that the recent Cochrane Systematic Review on Electronic Fetal heart rate Monitoring using the CTG has concluded that compared to intermittent auscultation, the use of CTG does not reduce the incidence of cerebral palsy or perinatal deaths [11]. However, it is associated with an increased incidence of both emergency caesarean sections and operative vaginal births [11].

\section{What is "Physiological Interpretation of CTG"?}

Individualization of care to each fetus is paramount to improve perinatal outcomes and to avoid the incidence of hypoxic-ischemic encephalopathy (HIE) and perinatal deaths. This is because each human fetus is different with different individual physiological reserves, different maternal and intrauterine environments, different uteroplacental perfusion, different thickness of the Wharton's jelly that prevents umbilical cord compression, different intensities of uterine contractions. Therefore, it is illogical to apply one set of clinical guidelines which stipulate arbitrary time limits on all human foetuses [12]. Physiological interpretation of CTG involves a deeper understanding of fetal oxygenation [13], as well as the pathophysiology of intrapartum hypoxia [14]. The classification and the management should not be based solely on the observed patterns on the CTG trace, but on the deeper understanding of the different types of intrapartum hypoxia $[14,15]$. It is vital to understand the compensatory fetal responses to ongoing repetitive hypoxic and mechanical stresses during labor, as well as the onset of fetal decompensation [16], so that timely and appropriate action can be taken to avoid hypoxicischemic encephalopathy and perinatal deaths, whilst at the same time avoiding unnecessary operative interventions to the mother by differentiating the "fetal stress response" from "fetal decompensation". Recently, 34 CTG experts on fetal physiology from 14 countries produced the first International Consensus Guidelines on physiological interpretation of CTG in 2018 [17].

\section{Physiological CTG interpretation and the use of fetal ECG (ST-Analyser or STAN)}

ST-Analyzer aims to detect the onset of negative energy balance within the fetal myocardial cells because of anaerobic metabolic and the production of lactic acid within the myocardial cells. Compared to an aerobic metabolism which generates sufficient energy source (ATPs), anaerobic metabolism leads to a reduction in myocardial energy production and resultant negative energy balance leading resulting in changes in the "ST segment" of the fetal ECG. However, instead of using standard guidelines in all human fetuses, it is essential to individualize care using fetal physiology. Moreover, it is also vital to detect pre-existing or chronic hypoxia [18], and other antenatal causes of fetal compromise [19], as these are contraindications for STAN monitoring. This is because such a fetus would have already exhausted the cardiac glycogen and other physiological reserves which are essential to mount an effective compensatory response to intrapartum hypoxic stress. Therefore, the STAN technology may not be able to recognize and detect ST segment changes due to the depletion of cardiac glycogen and resultant absence of potassium release within the myocardial cell leading to absence of ST segment changes. (Figure 1) illustrates the principles of using Physiological interpretation of CTG with STAN.

\section{Materials \& Methods}

This is a retrospective study at the Royal Went Hospital in South Wales following the introduction of STAN monitoring after training in Physiological Interpretation of CTG traces for approximately $70 \%$ of doctors and midwives prior to the use 


\section{Global Journal of Reproductive Medicine}

of STAN in clinical practice. NICE Guidelines were used for CTG interpretation with fetal scalp blood sampling (FBS) prior to the intervention. STAN Guidelines which were based on FIGO Guidelines were used with Physiological Interpretation of CTG without FBS after the intervention. Data on operative deliveries was obtained from the local hospital database and neonatal data were obtained from the Badger Net UK System. Total Caesarean section rate, emergency caesarean section rate for fetal compromise (i.e., "fetal distress"), operative vaginal delivery rate and spontaneous vaginal delivery (SVD) rate were analyzed for 19 months from 01 October 2014 to 30 April 2016. "Fetal Distress" was diagnosed if the observed features on the CTG trace met the criteria for "Pathological" (NICE) or "Abnormal" (STAN) pattern. Emergency caesarean section rate was defined when the woman has gone into a spontaneous or induced labor (i.e., after the onset of uterine activity). As this was retrospective study and no patient identifiable data was used. Therefore, according to the NHS Heath Research Authority Criteria, Ethics Approval was not required. The two-tailed Chi Square Test with Yate's correction was used for statistical analysis, and $p$ value of $<0.05$ was considered as statistically significant Table 1.

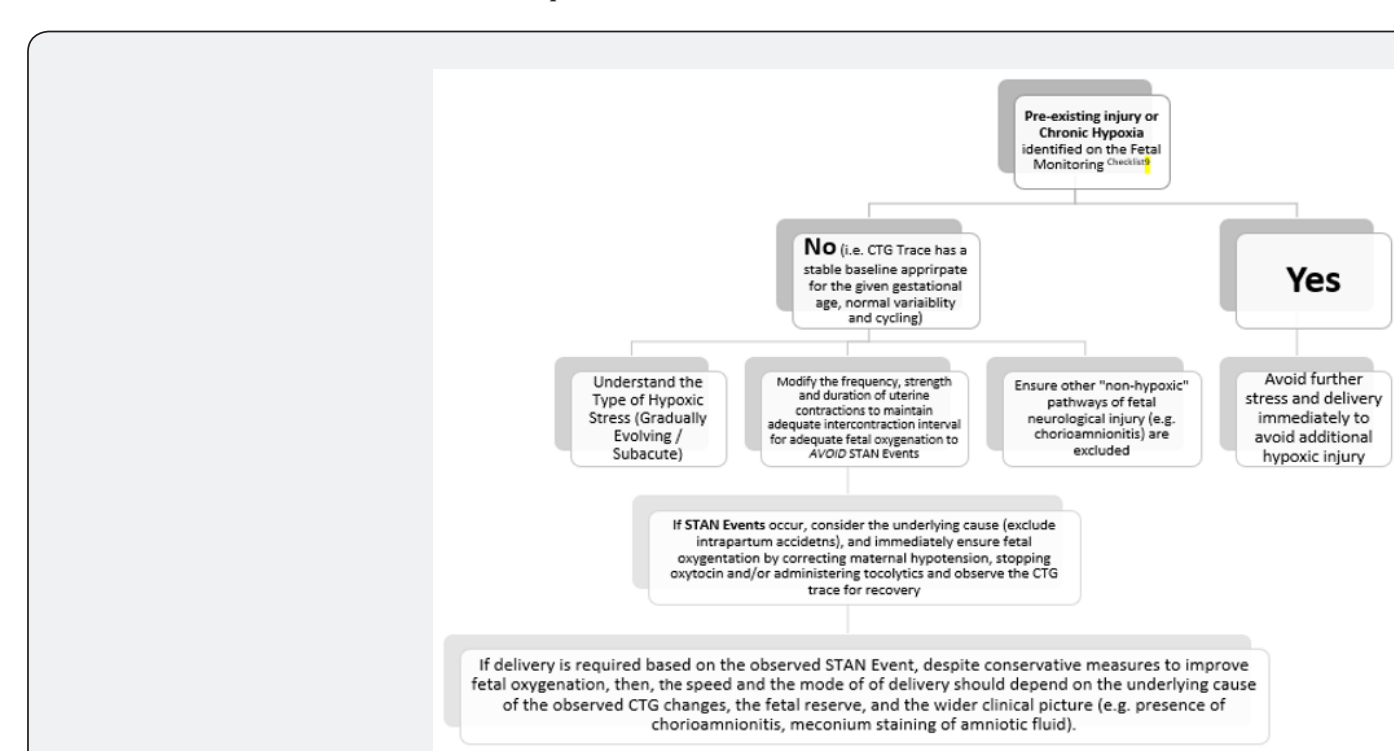

Figure 1: Principles of Physiological CTG Interpretation whilst using STAN (ST-Analysis).

Table 1: Rates of Emergency Caesarean Section for suspected fetal compromise ("Fetal Distress") before and after training on Physiological Interpretation of CTG and the introduction of STAN.

\begin{tabular}{|c|c|c|c|c|c|c|}
\hline & \multicolumn{2}{|c|}{ PRE } & & & & $P$ Value \\
\hline & 2012 & 2013 & \multirow{11}{*}{$\begin{array}{l}\text { Training on } \\
\text { Physiological } \\
\text { Interpretation }\end{array}$} & 2015 & 2016 & \\
\hline Overall C Section rate & $29.00 \%$ & $27.00 \%$ & & $24.00 \%$ & $22.30 \%$ & \\
\hline Emergency C section rate & $19.00 \%$ & $17.00 \%$ & & $14.00 \%$ & $12.30 \%$ & \\
\hline "Fetal Distress" (FD) & $28.00 \%$ & $34.00 \%$ & & $20.00 \%$ & $11.00 \%$ & \\
\hline Annual delivery rate & 3903 & 3833 & & 4124 & 3853 & \\
\hline EmCS & 742 & 652 & & 577 & 474 & \\
\hline EmCS FD & 208 & 222 & & 115 & 52 & \\
\hline Total Deliveries & \multicolumn{2}{|c|}{11676} & & \multicolumn{2}{|c|}{7977} & \\
\hline Em CS FD & \multicolumn{2}{|c|}{650} & & \multicolumn{2}{|c|}{168} & \\
\hline non EmCS FD & \multicolumn{2}{|c|}{11026} & & \multicolumn{2}{|c|}{7809} & \\
\hline EmCS FD as percentage of all deliveries & \multicolumn{2}{|c|}{$5.50 \%$} & & \multicolumn{2}{|c|}{$2.10 \%$} & $<.0001$ \\
\hline
\end{tabular}




\section{Global Journal of Reproductive Medicine}

Result

There were 7977 deliveries during the 19-month period from zero 1 October 2014 to 30 April 2016. The average total Caesarean section rate was $23.5 \%$ and the emergency Caesarean section rate for suspected fetal compromise ("fetal distress") was $13.6 \%$, There was a trend in the reduction in the overall caesarean section rate as well as a reduction in the intrapartum emergency caesarean sections performed for "fetal distress" immediately after the introduction of STAN following training on Physiological Interpretation of CTG (Figure 2). The emergency caesarean section rate for "fetal distress" reduced from 35\% to $11 \%$ (Figure 3). The overall rate of emergency caesarean section for fetal distress fell from $5.57 \%$ from $2012-14$ to $2.10 \%$ after the training on physiological interpretation of the CTG and the introduction of STAN technology (Figure 4), and this reduction was statistically significant $(\mathrm{p}<0.0001)$. The rate of neonatal encephalopathy (NNE) was comparable to the UK average, However, the rate of hypoxic ischaemic encephalopathy (HIE) due to CTG misinterpretation was reduced by $50 \%$ following the training on Physiological Interpretation of CTG, followed by the introduction of STAN monitoring (Figure 5).

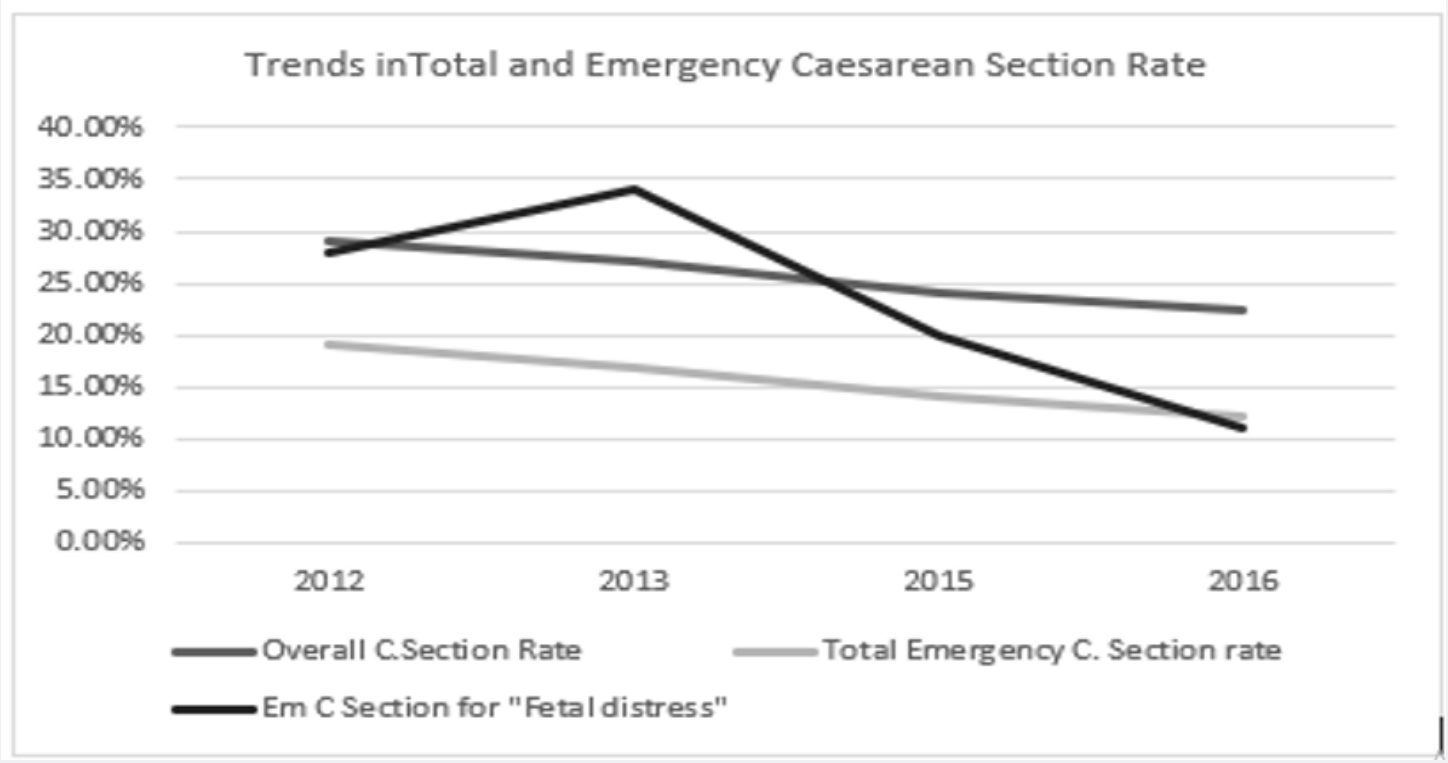

Figure 2: The Modes of Delivery following training on Physiological Interpretation of CTG and introduction of STAN technology.

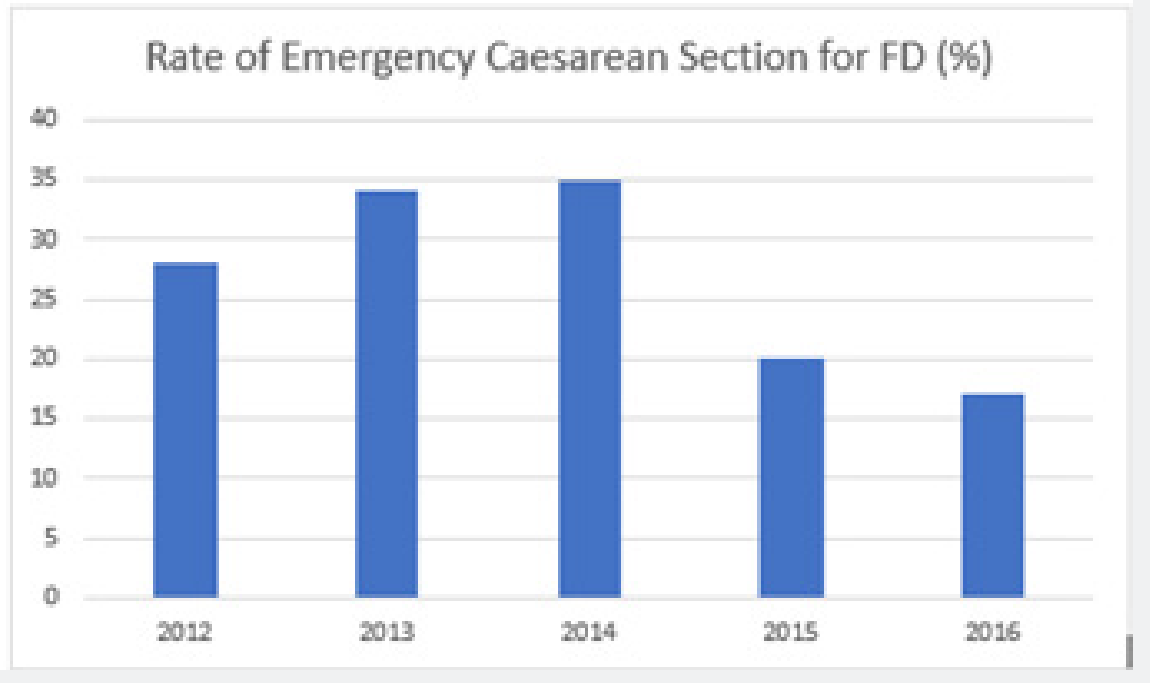

Figure 3: Reduction in the emergency caesarean section rate for "fetal distress" as a percentage of all emergency caesarean sections after the intervention in 2014. 


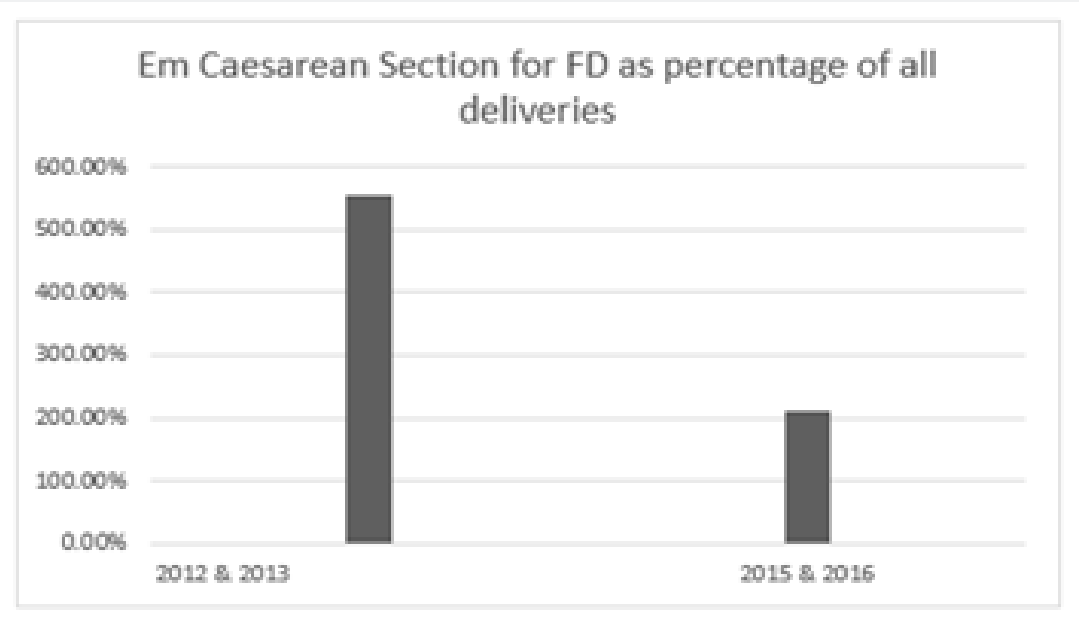

Figure 4: Reduction in the emergency caesarean section rate after the intervention as a percentage of all caesarean sections.

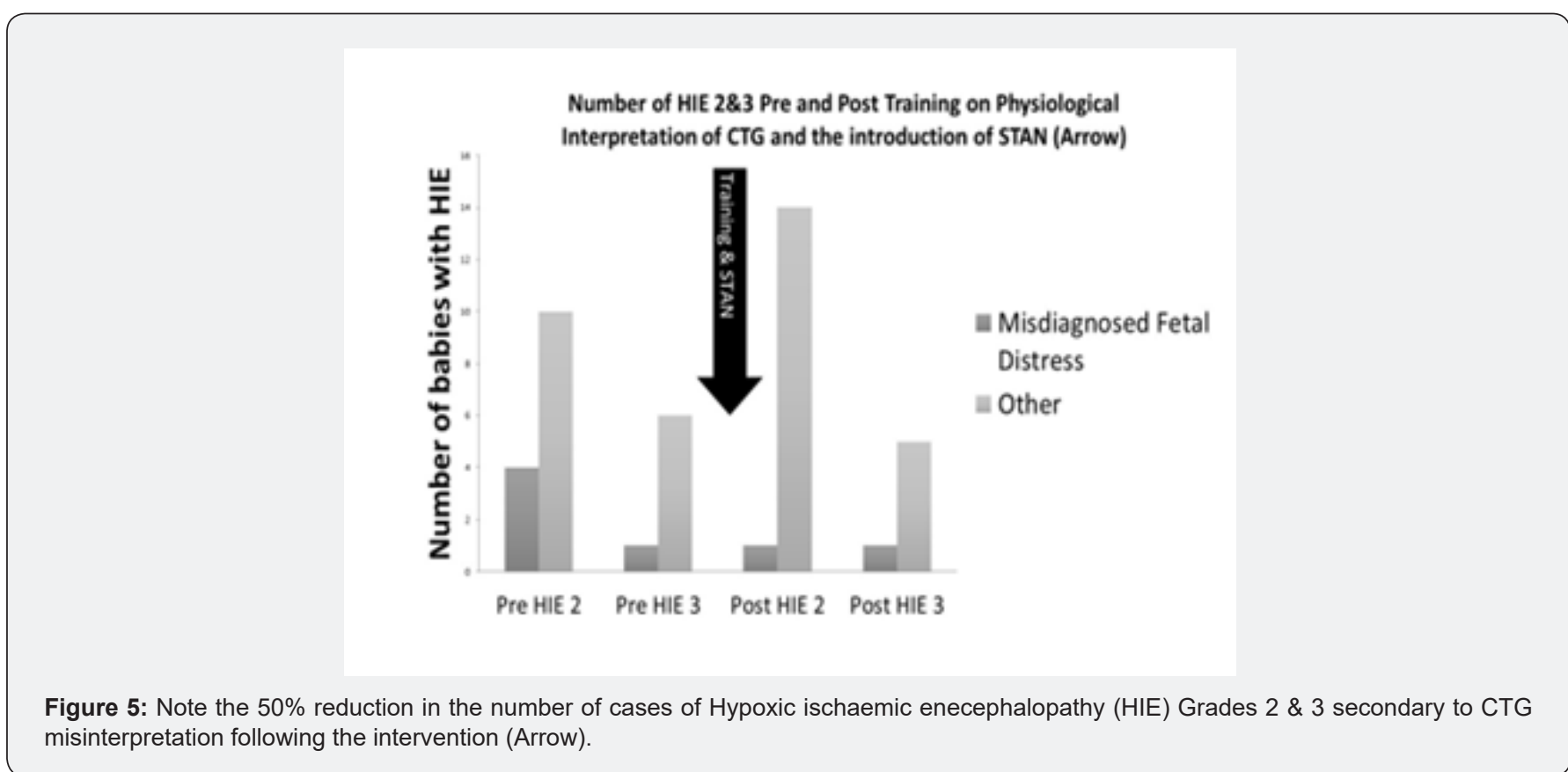

\section{Discussion}

Our study illustrates that intense training on Physiological Interpretation of CTG prior to the introduction of the STAN technology as an adjunct to CTG monitoring results in a reduction in intrapartum emergency caesarean section rate performed for suspected fetal compromise. The hypoxic-ischaemic encephalopathy (HIE) rate (Grades 2 \& 3) secondary to CTG misinterpretation also reduce from $34 \%$ to $17 \%$ following the intense training on Physiological CTG Interpretation and the introduction of the STAN technology. This rate is approximately $50 \%$ lower than the national reported rate, because the Each Baby Counts Report produced by the Royal College of Obstetricians and Gynecologists (RCOG) concluded that 33\% of poor perinatal outcomes in the UK was secondary to CTG misinterpretation [20]. A recent meta-analysis of six randomized controlled trials (RCTs) comprising of $>26,000$ babies has concluded that the use of STAN is associated with a $36 \%$ statistically significant reduction in neonatal metabolic acidosis, and a modest (8\%) reduction in operative vaginal births [21]. However, there has been no reduction in intrapartum emergency caesarean sections for suspected fetal compromise. The main reason for this lack of beneficial effect appears to be the reliance on "pattern recognition" whilst classifying the CTG traces according to the STAN guidelines, with which may lead to significant inter and intra-observer variability. Because a "pathological" or an "abnormal" CTG is associated with approximately $>90 \%$ false-positive rate, and a significant inter and intra observer variation with "pattern recognition", it is not 
surprising that there was no reduction in the rate of intrapartum emergency caesarean sections for "fetal distress" in the studies analyzed. Observational studies have shown an improvement of perinatal outcomes with continued use of the STAN technology [22-25], which suggests that with continued use, clinicians gradually acquire a deeper knowledge of fetal pathophysiological responses to intrapartum hypoxic stress resulting in progressive improvement in neonatal outcomes.

\section{Are our results reproducible?}

Although, other maternity units observed a progressive improvement in perinatal outcomes with continued use of STAN technology [22-25] and resultant improvement in physiological knowledge, we wanted to train midwives and obstetricians on Physiological Interpretation of CTG prior to the introduction of STAN technology to avoid over reaction to "patterns" and to reduce the inter and intra-observer variability. A large teaching hospital in London reported that following the introduction of STAN technology in 2002, the analysis of the first 1502 cases showed no improvement in perinatal outcomes or their emergency caesarean section rate [26]. This study reported a metabolic acidosis rate of $2.8 \%$, and 14 cases of neonatal encephalopathy (NNE) amongst 1502 babies monitored by STAN technology. The authors concluded that "in our unit, the introduction of STAN technology has not changed the incidence of emergency operator delivery or NNE", and stated "better training, assessment and supervision of users may help improve outcome" [26]. After the introduction of an intensive training on physiological interpretation of CTG as well as a mandatory competency testing for clinicians on CTG interpretation, authors from the same hospital reported a $50 \%$ reduction in the intrapartum emergency caesarean sections, and a reduction of neonatal metabolic acidosis rate from $2.8 \%$ to $0.6 \%$ [27]. Furthermore, there was approximately a $50 \%$ reduction in the HIE rate, when staff were trained on physiological CTG interpretation whilst using the STAN technology. Therefore, we learned from the experience of this maternity unit, and introduced STAN technology only after training on physiological interpretation of CTG. Our results show that such an approach can led to a reduction in the intrapartum emergency caesarean section rate as well as a reduction in the HIE rate secondary to CTG misinterpretation. Increasing caesarean section rate is associated with serious maternal morbidity and mortality worldwide, which include uterine rupture and Placenta Acreta Spectrum (PAS) disorders in subsequent pregnancies. Therefore, there is an urgent need to reduce the rising caesarean section rate to improve maternal and perinatal outcomes. Although, fetal FBS was used as an "adjunct" to CTG interpretation in our unit until 2014 to reduce the false positive rate of the CTG, we completely stopped FBS after the training on Physiological Interpretation of CTG. Not only the physiological and scientific basis of FBS has been recently questioned [28,29], the recent Cochrane Systematic Review has suggested that the use of fetal scalp blood sampling does not improve perinatal outcomes [30]. A recent prospective multicenter trial from 44 maternity units in the UK has also reported that FBS did not improve perinatal outcomes and increased intrapartum operative interventions by $60 \%$ [31]. The "Achilles Heel" of the STAN technology is the misinterpretation of the CTG trace due to inter and intra-observer variability as a result of using guidelines which are based on "pattern recognition" on all human fetuses with different individual physiological reserves. The occurrence of a "significant STAN Event" does not require the same action within a stipulated time frame in all human fetuses because not only the individual reserve of each fetus is different, the intensity and the duration of hypoxia is also different. Therefore, physiological interpretation of CTG was introduced to help individualize care for each human fetus, and to develop a deeper understanding regarding the type of intrapartum hypoxic stress and the fetal response to the ongoing stress. Physiological interpretation of CTG with the use of STAN is aimed at overcoming the shortcomings of using a population-based "pattern-recognition" guidelines on all human fetuses. The role of such intense training on CTG interpretation whilst using STAN has been emphasized earlier $[32,33]$. We recognize that out study has several limitations. It is a retrospective, single center study, and therefore, it is associated with the bias associated with any retrospective analysis. We did not make any significant changes in staffing or other processes in our maternity unit which may have influenced the outcome. Better understanding of fetal physiology resulted in complete stopping of FBS and having no "suspicious or pathological CTG" traces, and in individualization of care.

\section{Conclusion}

Our study shows that intense training on physiological interpretation of CTG prior to the introduction of the STAN helps in reducing intrapartum emergency caesarean sections and the HIE rate secondary to CTG misinterpretation. One may argue that such an approach, focused on intense training on physiological CTG interpretation and introduction of STAN technology is costly. However, airlines do provide an intense training to their pilots to ensure passenger safety. CTG misinterpretation and its resultant medicolegal implications not only has financial implications to hospitals, but it also has an enormous human cost to women, families and the society as well as the midwives and obstetricians who are involved in adverse incidents. Therefore, based on our experience and outcomes, we recommend physiological CTG interpretation and the introduction of STAN technology as an adjunctive test to reduce the false positive rate of the CTG trace and to improve maternal and perinatal outcomes.

\section{Contribution to Authorship}

SP and EC conceived the idea and designed the study. ER and LP collected and analyzed the data. EC and SP co-wrote the manuscript. All authors reviewed and edited the manuscript. 


\section{Global Journal of Reproductive Medicine}

\section{Conflict of Interest}

ER, LP and SP declare no conflict of interest. E. C. conducts several Master classes on Physiological Interpretation of CTG and fetal ECG in the UK, Europe, Asia, and Australia and has been the co-organizer of the Intrapartum Fetal Surveillance Course at the Royal College of Obstetricians and Gynecologists (RCOG) and he was a member of the Editorial Board for NHS e-learning on CTG. He is the Course lead for the Baby Lifeline CTG and Neoventa Academy Masterclasses. Several organizers and hospitals of some of these Masterclasses have received sponsorships from Philips, Neoventa, Euroking, Huntleigh, K2, Cardiac Services, and other industry to support these Masterclasses. However, E.C. does not have any financial or managerial interests in any pharmaceutical or medical device industry. EC was one of the 3-member guideline development group which revised the international FIGO Guidelines on CTG in 2015, and he was on the Editorial Board which produced the first International Consensus Guidelines on Physiological Interpretation of CTGs in conjunction with 34 CTG Experts from 14 countries.

\section{Acknowledgement}

The authors would like to thank Ms Amy Robb for performing the statistical analysis.

\section{References}

1. Ayres de Campos D, Arteiro D, Costa Santos C, Bernardes J (2011) Knowledge of adverse neonatal outcome alters clinicians' interpretation of the intrapartum cardiotocograph. An Int J Obstet Gynaecol 118: 978984.

2. (2014) National Institute of Clinical Excellence. Intrapartum care: care of healthy women and their babies during labour. NICE Clinical Guideline

3. (2009) American Congress of Obstetricians and Gynecologists. Intrapartum fetal heart rate monitoring: nomenclature, interpretation, and general management principles. Practice Bulletin 106.

4. Amer Wahlin I, Arulkumaran S, Hagberg H, Marsál K, Visser GH (2007) Fetal electrocardiogram: ST waveform analysis in intrapartum surveillance. BJOG 114(10): 1191-1193.

5. Donker DK, van Geijn HP and Hasman A (1993) Interobserver variation in the assessment of fetal heart rate recordings. Eur J Obstet Gynecol Reprod Biol 52: 21-28.

6. Lidegaard O, Bøttcher LM and Weber T (992) Description, evaluation and clinical decision making according to various fetal heart rate patterns. Inter-observer and regional variability. Acta Obstet Gynecol Scand 71: 48-53.

7. Blix E, Sviggum O, Koss KS (2003) Inter-observer variation in assessment of 845 labor admission tests: comparison between midwives and obstetricians in the clinical setting and two experts. BJOG 110: 1-5.

8. Ayres de Campos D, Arteiro D, Costa-Santos C (2011) Knowledge of adverse neonatal outcome alters clinicians' interpretation of the intrapartum cardiotocograph. BJOG 118: 978-984.

9. Nielsen PV, Stigsby B, Nickelsen C (1987) Intra- and inter-observer variability in the assessment of intrapartum cardiotocograms. Acta Obstet Gynecol Scand 66: 421-424.
10. Reif P, Schott S, Boyon C (2016) Does knowledge of fetal outcome influence the interpretation of intrapartum cardiotocography and subsequent clinical management? A multicentre European study. BJOG 123: 2208-2217.

11. Alfirevic Z, Devane D, Gyte GML (2017) Continuous cardiotocography (CTG) as a form of electronic fetal moni-toring (EFM) for fetal assessment during labour. Cochrane Database Syst Rev P. 2.

12. Chandraharan E, Tahan ME, Pereira S (2016) Each Fetus Matters: An Urgent Paradigm Shift is needed to Move away from the Rigid "CTG Guideline Stickers to Individualize Intrapartum Fetal Heart Rate Monitoring and to improve Perinatal Outcomes. Obstet Gynecol Int J 5(4): 00168.

13. Gracia Perez Bonfils A, Chandraharan E (2017) Fetal oxygenation (In:) Chandraharan E, Handbook of CTG interpretation. From patterns to physiology. Cambridge (MA): Cambridge University Press 6-12.

14. Chandraharan E, Arulkumaran S (2007) Prevention of birth asphyxia: responding appropriately to cardiotocograph (CTG) traces. Best Pract Res Clin Obstet Gynaecol 21: 609-624.

15. Pinas A, Chandraharan E (2016) Continuous cardiotocography during labour: analysis, classification and management. Best Pract Res Clin Obstet Gynaecol 30: 33-47.

16. Jia YJ, Chen X, Cui HY, Whelehan V, Archer A, et al. (2019) Physiological CTG interpretation: the significance of baseline fetal heart rate changes after the onset of decelerations and associated perinatal outcomes. J Matern Fetal Neonatal Med 18: 1-6.

17. https://physiological-ctg.com/guideline/guideline.html

18. Pereira S, Chandraharan E (2017) Recognition of chronic hypoxia and pre-existing foetal injury on the cardiotocograph (CTG): Urgent need to think beyond the guidelines. Porto Biomed J 2: 124-129.

19. Pereira S, Ingram C, Gupta N, Singh M, Chandraharan E (2020) Recognising Fetal Compromise in the Cardiograph during the Antenatal Period: Pearls and Pitfalls. Asian Journal of Medicine and Health 18(9): 72-83.

20. https://www.rcog.org.uk/globalassets/documents/guidelines/ research report-2018-11-12.pdf

21. Blix E, Brurberg KG, Reierth E (2017) ST waveform analysis vs. cardiotocography alone for intrapartum fetal monitoring: a systematic review and meta-analysis of randomized trials. Acta Obstet Gynecol Scand 95: 16-27.

22. Timonen S (2012) Prevention of intrapartum hypoxia with STanalysis-10 years' experience at the Turku University Hospital. Am J Obstet Gynecol 206: s279.

23. Kessler J, Moster D, Albrechtsen S (2013) Intrapartum monitoring of high-risk deliveries with ST analysis of the fetal electrocardiogram: an observational study of 6010 deliveries. Acta Obstet Gynecol Scand 92: 75-84.

24. Landman AJEMC, Immink Duijker ST, Mulder EJH, Koster MPH, Xodo S, et al. (2019) Significant reduction in umbilical artery metabolic acidosis after implementation of intrapartum ST waveform analysis of the fetal electrocardiogram. Am J Obstet Gynecol 221(1): 63. e1-e13.

25. Norén H, Carlsson A (2010) Reduced prevalence of metabolic acidosis at birth: an analysis of established STAN usage in the total population of deliveries in a Swedish district hospital. Am J Obstet Gynecol 202(6): 546. e1-7.

26. Doria V, Papageorghiou A, Gustafsson A, Ugwumadu A, Farrer K et al. (2007) Review of the first 1502 cases of ECG-ST waveform analysis during labour in a teaching hospital. An International Journal of Obstetrics \& Gynaecology 114: 1202-1207. 
27. Chandraharan E, Lowe V, Ugwumadu A, Arulkumaran S (2013) Impact of Fetal ECG (STAN) and competency-based training on intrapartum interventions and perinatal outcomes at a Teaching Hospital in London: 5 Year Analysis. BJOG 120: 428-429.

28. Chandraharan E, Wiberg N (2014) Fetal scalp blood sampling during labor: an appraisal of the physiological basis and scientific evidence. Acta Obstet Gynecol Scand 93: 544-547.

29. Chandraharan E (2014) Fetal scalp blood sampling during labour: is it a useful diagnostic test or a historical test that no longer has a place in modern clinical obstetrics? BJOG 121: 1056-160.

30. Alfirevic Z, Devane D, Gyte GML (2019) Continuous cardiotocography (CTG) as a form of electronic fetal moni-toring (EFM) for fetal assessment during labour. Cochrane Database Syst Rev P. 2.

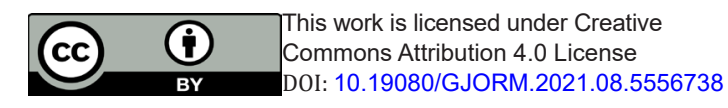

31. Al Wattar BH, Lakhiani A, Sacco A (2019) AB-FAB Study Group. Evaluating the value of intrapartum fetal scalp blood sampling to predict adverse neonatal outcomes: a UK multicentre observational study. Eur J Obstet Gynecol Reprod Biol 240: 62-67.

32. Bhide A, Chandraharan E, Acharya G (2016) Fetal monitoring in labor: Implications of evidence generated by new systematic review. Acta Obstet Gynecol Scand 95(1): 5-8.

33. Chandraharan E (2018) Foetal electrocardiograph (ST-analyzer or STAN) for intrapartum foetal heart rate monitoring: a friend or a foe. The Journal of Maternal-Fetal \& Neonatal Medicine 31(1): 123-127.

Your next submission with Juniper Publishers
will reach you the below assets
- Quality Editorial service
- Swift Peer Review
- Reprints availability
- E-prints Service
- Manuscript Podcast for convenient understanding
- Global attainment for your research
- Manuscript accessibility in different formats
( Pdf, E-pub, Full Text, Audio)
- Unceasing customer service
Track the below URL for one-step submission
https://juniperpublishers.com/online-submission.php

